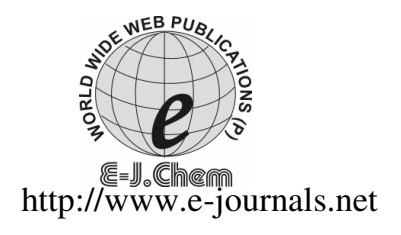

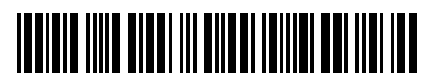

ISSN: 0973-4945; CODEN ECJHAO

E-Journal of Chemistry 2012, 9(1), 340-344

\title{
Development, Estimation and Validation of Lisinopril in Bulk and its Pharmaceutical Formulation by HPLC Method
}

\author{
V. BHASKARA RAJU and A. LAKSHMANA RAO* \\ ${ }^{*}$ V.V. Institute of Pharmaceutical Sciences, Gudlavalleru- 521 356, A.P., India \\ Sri Vasavi Institute of Pharmaceutical Sciences \\ Tadepalligudem- 534 101, A.P., India \\ dralrao@gmail.com
}

Received 25 June 2011; Accepted 13 August 2011

\begin{abstract}
An accurate and precise HPLC method was developed for the determination of lisinopril. Separation of the drug was achieved on a reverse phase $\mathrm{C}_{8}$ column using a mobile phase consisting of phosphate buffer and methanol in the ratio of $35: 65 \mathrm{v} / \mathrm{v}$. The flow rate was $0.8 \mathrm{~mL} / \mathrm{min}$ and the detection wavelength was $215 \mathrm{~nm}$. The linearity was observed in the range of $20-60 \mu \mathrm{g} / \mathrm{mL}$ with a correlation coefficient of 0.9992 . The proposed method was validated for its linearity, accuracy, precision and robustness. This method can be employed for routine quality control analysis of lisinopril in tablet dosage forms.
\end{abstract}

Keywords: Lisinopril, Estimation, RP-HPLC, Validation, Tablets

\section{Introduction}

Lisinopril is a potent, competitive inhibitor of angiotensin-converting enzyme (ACE), the enzyme responsible for the conversion of angiotensin I (ATI) to angiotensin II (ATII). ATII regulates blood pressure and is a key component of the renin-angiotensin-aldosterone system (RAAS). Lisinopril is indicated for the treatment of hypertension. It may be used alone as initial therapy or concomitantly with other classes of antihypertensive agents. Lisinopril is indicated as adjunctive therapy in the management of heart failure in patients who are not responding adequately to diuretics and digitalis. Lisinopril is chemically described as $(S)$-1-[ $N^{2}$-(1-carboxy-3-phenylpropyl)- $L$-lysyl]- $L$-proline dihydrate ${ }^{1}$ (Figure 1$)$. A few spectroscopic $^{2,3}$, HPLC $^{4-6}$ and LC-MS ${ }^{7}$ methods were reported earlier for the determination of lisinopril in bulk and pharmaceutical dosage forms. In the present study the authors report a rapid, sensitive, accurate and precise HPLC method for the estimation of lisinopril in bulk and in tablet dosage forms. 


\section{Experimental}

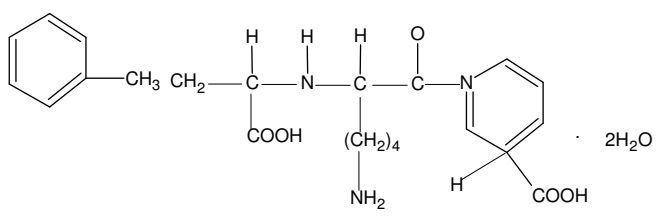

Figure 1. Chemical structure of lisinopril

The analysis of the drug was carried out on a waters HPLC system equipped with a reverse phase xterra $\mathrm{C}_{8}$ column $(150 \mathrm{~mm} \times 4.6 \mathrm{~mm} ; 3.5 \mu \mathrm{m})$, a 2695 binary pump, a $20 \mu \mathrm{L}$ injection loop and a 2487 dual absorbance detector and running on waters empower software.

\section{Chemicals and solvents}

The reference sample of lisinopril was supplied by Sun Pharmaceutical Industries Ltd., Baroda. HPLC grade water and acetonitrile were purchased from E. Merck (India) Ltd., Mumbai. Potassium dihydrogen phosphate and orthophosphoric acid of AR Grade were obtained from S.D. Fine Chemicals Ltd., Mumbai.

\section{Preparation of phosphate buffer ( $\mathrm{pH}$ 3.0)}

Seven grams of $\mathrm{KH}_{2} \mathrm{PO}_{4}$ was weighed into a $1000 \mathrm{~mL}$ beaker, dissolved and diluted to $1000 \mathrm{~mL}$ with HPLC water. $2 \mathrm{~mL}$ of triethyl amine was added and $\mathrm{pH}$ adjusted to 3.0 with orthophosporic acid.

\section{Preparation of mobile phase and diluents}

$350 \mathrm{~mL}$ of the phosphate buffer was mixed with $650 \mathrm{~mL}$ of methanol. The solution was degassed in an ultrasonic water bath for 5 minutes and filtered through $0.45 \mu$ filter under vacuum.

\section{Procedure}

A mixture of buffer and methanol in the ratio of $35: 65 \mathrm{v} / \mathrm{v}$ was found to be the most suitable mobile phase for ideal separation of lisinopril. The solvent mixture was filtered through a $0.45 \mu$ membrane filter and sonicated before use. It was pumped through the column at a flow rate of $0.8 \mathrm{~mL} / \mathrm{min}$. The column was maintained at ambient temperature. The pump pressure was set at 800 psi. The column was equilibrated by pumping the mobile phase through the column for at least $30 \mathrm{~min}$ prior to the injection of the drug solution. The detection of the drug was monitored at $215 \mathrm{~nm}$. The run time was set at $6 \mathrm{~min}$. Under these optimized chromatographic conditions the retention time obtained for the drug was $2.298 \mathrm{~min}$. A typical chromatogram showing the separation of the drug is given in Figure 2.

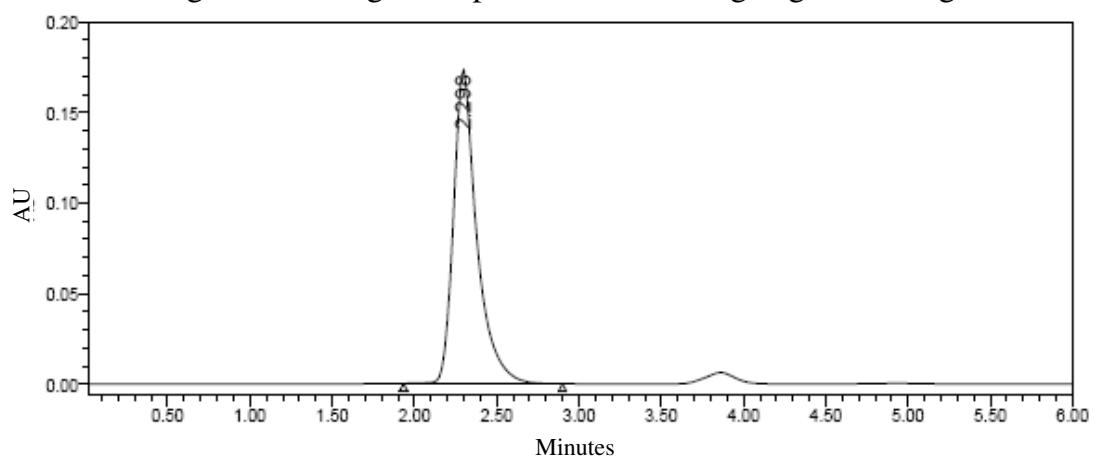

Figure 2. Typical chromatogram of lisinopril 


\section{Calibration plot}

About $25 \mathrm{mg}$ of lisinopril was weighed accurately, transferred into a $100 \mathrm{~mL}$ volumetric flask and dissolved in $25 \mathrm{~mL}$ of a 35:65v/v mixture of phosphate buffer and methanol. The solution was sonicated for $15 \mathrm{~min}$ and the volume made up to the mark with a further quantity of the diluent to get a $100 \mu \mathrm{g} / \mathrm{mL}$ solution. From this, a working standard solution of the drug $(40 \mu \mathrm{g} / \mathrm{mL})$ was prepared by diluting $2 \mathrm{~mL}$ of the above solution to $10 \mathrm{~mL}$ in a volumetric flask. Further dilutions ranging from $20-60 \mu \mathrm{g} / \mathrm{mL}$ were prepared from the solution in $10 \mathrm{~mL}$ volumetric flasks using the above diluent. $20 \mu \mathrm{L}$ of each dilution was injected six times into the column at a flow rate of $0.8 \mathrm{~mL} / \mathrm{min}$ and the corresponding chromatograms were obtained. From these chromatograms, the average area under the peak of each dilution was computed. The calibration graph constructed by plotting concentration of the drug against peak area was found to be linear in the concentration range of $20-60 \mu \mathrm{g} / \mathrm{mL}$ of the drug. The relevant data are furnished in Table 1 . The regression equation of this curve was computed. This regression equation was later used to estimate the amount of lisinopril in tablet dosage form.

Table 1. Calibration data of the method

\begin{tabular}{cc}
\hline Concentration, $\mu \mathrm{g} / \mathrm{mL}$ & Mean peak area $(\mathrm{n}=5)$ \\
\hline 20 & 862515 \\
30 & 1282509 \\
40 & 1699129 \\
50 & 2045597 \\
60 & 2426870 \\
\hline
\end{tabular}

\section{Validation of the proposed method}

The specificity, linearity, precision, accuracy, limit of detection, limit of quantification, robustness and system suitability parameters were studied systematically to validate the proposed HPLC method for the determination of lisinopril. Solution containing $40 \mu \mathrm{g} / \mathrm{mL}$ of lisinopril was subjected to the proposed HPLC analysis to check intra-day and inter-day variation of the method and the results are furnished in Table 2. The accuracy of the HPLC method was assessed by analyzing solutions of lisinopril at 50,100 and 150\% concentrated levels by the proposed method. The results are furnished in Table 3. The system suitability parameters are given in Table 4.

Table 2. Precision of the proposed HPLC method

\begin{tabular}{ccc}
\hline Concentration of lisinopril, & \multicolumn{2}{c}{ Peak area } \\
\cline { 2 - 3 } $40 \mu \mathrm{g} / \mathrm{mL}$ & Intra-day & Inter-day \\
\hline Injection-1 & 1713758 & 1759603 \\
Injection-2 & 1700467 & 1765945 \\
Injection-3 & 1704762 & 1773629 \\
Injection-4 & 1716273 & 1778465 \\
Injection-5 & 1752656 & 1788460 \\
Average & 1717583 & 1773220 \\
Standard Deviation & 20638.4 & 11161.1 \\
\%RSD & 1.20 & 0.63 \\
\hline
\end{tabular}


Table 3. Accuracy studies

\begin{tabular}{ccccc}
\hline Concentration & $\begin{array}{c}\text { Amount } \\
\text { added, mg }\end{array}$ & $\begin{array}{c}\text { Amount } \\
\text { found, mg }\end{array}$ & \% Recovery & $\begin{array}{c}\text { \% Mean } \\
\text { recovery }\end{array}$ \\
\hline $50 \%$ & 21.0 & 21.116 & $100.55 \%$ & \\
$100 \%$ & 40.0 & 39.941 & $99.85 \%$ & $100.02 \%$ \\
$150 \%$ & 59.50 & 59.294 & $99.65 \%$ & \\
\hline
\end{tabular}

Table 4. System suitability parameters

\begin{tabular}{cc}
\hline Parameter & Result \\
\hline Linearity, $\mu \mathrm{g} / \mathrm{mL}$ & $20-60$ \\
Correlation coefficient & 0.9992 \\
Theoretical plates $(\mathrm{N})$ & 2348 \\
Tailing factor & 1.5 \\
LOD,$\mu \mathrm{g} / \mathrm{mL}$ & 0.03 \\
LOQ,$\mu \mathrm{g} / \mathrm{mL}$ & 0.12 \\
\hline
\end{tabular}

\section{Estimation of lisinopril in tablet dosage form}

Two commercial brands of tablets were chosen for testing the suitability of the proposed method to estimate lisinopril in tablet formulation. Twenty tablets were weighed and powdered. An accurately weighed portion of this powder equivalent to $25 \mathrm{mg}$ of lisinopril was transferred into a $100 \mathrm{~mL}$ volumetric flask and dissolved in $25 \mathrm{~mL}$ of a $35: 65 \mathrm{v} / \mathrm{v}$ mixture of phosphate buffer and methanol. The contents of the flask were sonicated for $15 \mathrm{~min}$ and a further $25 \mathrm{~mL}$ of the diluent was added, the flask was shaken continuously for $15 \mathrm{~min}$ to ensure complete solubility of the drug. The volume was made up with the diluent and the solution was filtered through a $0.45 \mu$ membrane filter. This solution containing $40 \mu \mathrm{g} / \mathrm{mL}$ of lisinopril was injected into the column six times. The average peak area of the drug was computed from the chromatograms and the amount of the drug present in the tablet dosage form was calculated by using the regression equation obtained for the pure drug. The relevant results are furnished in Table 5 .

Table 5. Assay and recovery studies

\begin{tabular}{cccc}
\hline Formulation & Label claim, mg & Amount found, $\mathrm{mg}$ & \% Amount found \\
\hline Formulation 1 & 40 & 40.003 & 100.0 \\
Formulation 2 & 40 & 39.992 & 99.97 \\
\hline
\end{tabular}

\section{Results and Discussion}

In the proposed method, the retention time of lisinopril was found to be $2.298 \mathrm{~min}$. Quantification was linear in the concentration range of $20-60 \mu \mathrm{g} / \mathrm{mL}$. The regression equation of the linearity plot of concentration of lisinopril over its peak area was found to be $Y=106604.8+38917.98 X\left(r^{2}=0.9992\right)$, where $X$ is the concentration of lisinopril $(\mu \mathrm{g} / \mathrm{mL})$ and $\mathrm{Y}$ is the corresponding peak area. The number of theoretical plates calculated was 2348 , which indicates efficient performance of the column. The limit of detection and limit of quantification were found to be $0.03 \mu \mathrm{g} / \mathrm{mL}$ and $0.12 \mu \mathrm{g} / \mathrm{mL}$ respectively, which indicate the sensitivity of the method. The use of phosphate buffer and methanol in the ratio of $35: 65 \mathrm{v} / \mathrm{v}$ resulted in peak with good shape and resolution. The high percentage of recovery indicates that the proposed method is highly accurate. No interfering peaks were found in the chromatogram of the formulation within the run time indicating that excipients used in tablet formulation did not interfere with the estimation of the drug by the proposed HPLC method. 


\section{Conclusion}

The proposed HPLC method is rapid, sensitive, precise and accurate for the determination of lisinopril and can be reliably adopted for routine quality control analysis of lisinopril in its tablet dosage form.

\section{Acknowledgment}

The authors are thankful to M/s Sun Pharmaceutical Industries Ltd., Baroda for providing a reference sample of lisinopril.

\section{References}

1. www.drugs.com/lisinopril.html

2. Jamakhandi C M, Javali C, Disouza J I, Chougule U S and Mullani A K, Int J Pharm Pharm Sci., 2011, 3(2), 185-187.

3. Permender R, Sushila R, Shyama T and Vikash K, Int J Pharm Tech Res., 2010, 2(1), 556-562.

4. El-Emam A A, Hansen S H, Mohamed A M, El-Ashry S M and El-Sherbiny D T, $J$ Pharm Biomed Anal., 2004, 34(1), 35-44.

5. Beasley C A, Shaw J, Zhao Z and Reed R A, J Pharm Biomed Anal., 2005, 37(3), 559-567.

6. Tzvetkova D, Obreshkova D and Pencheva I V, Acta Pharm Turc., 2005, 47, 179-187.

7. Zhou N, Liang Y, Chen B, Wang P, Chen X and Lu F, J Chromatogr Sci., 2008, 46, 848-853. 


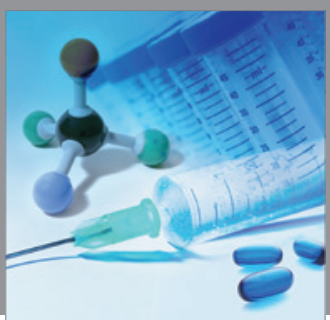

International Journal of

Medicinal Chemistry

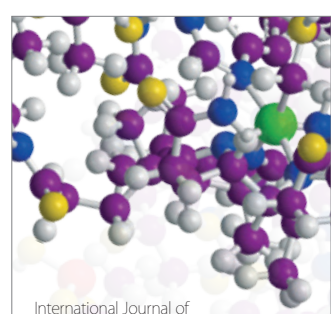

Carbohydrate Chemistry

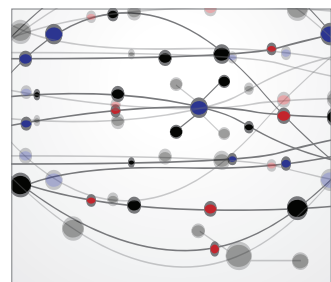

The Scientific World Journal
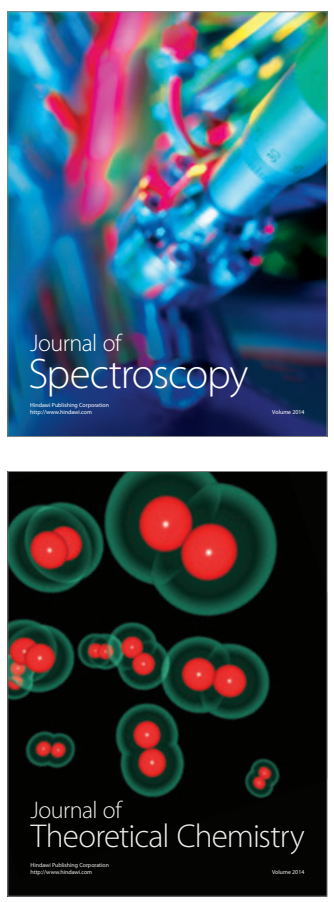
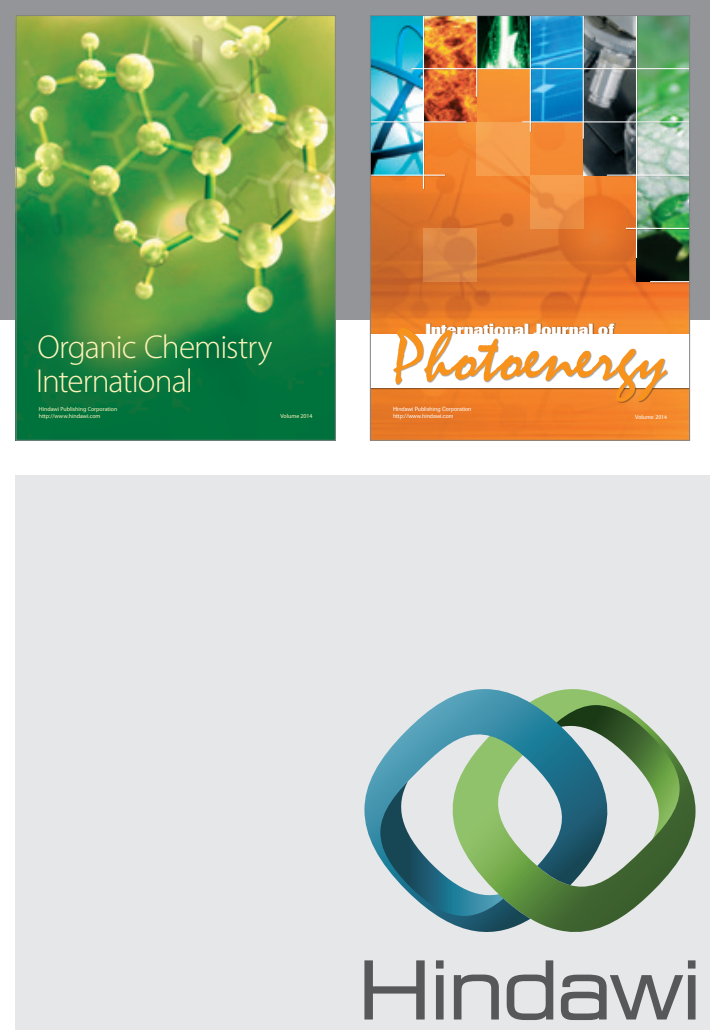

Submit your manuscripts at

http://www.hindawi.com
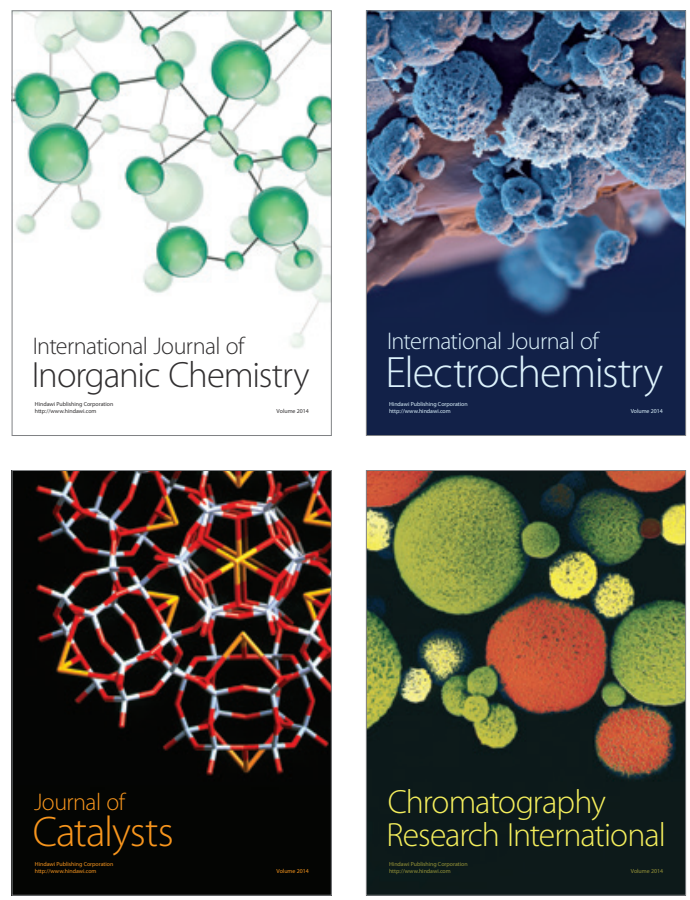
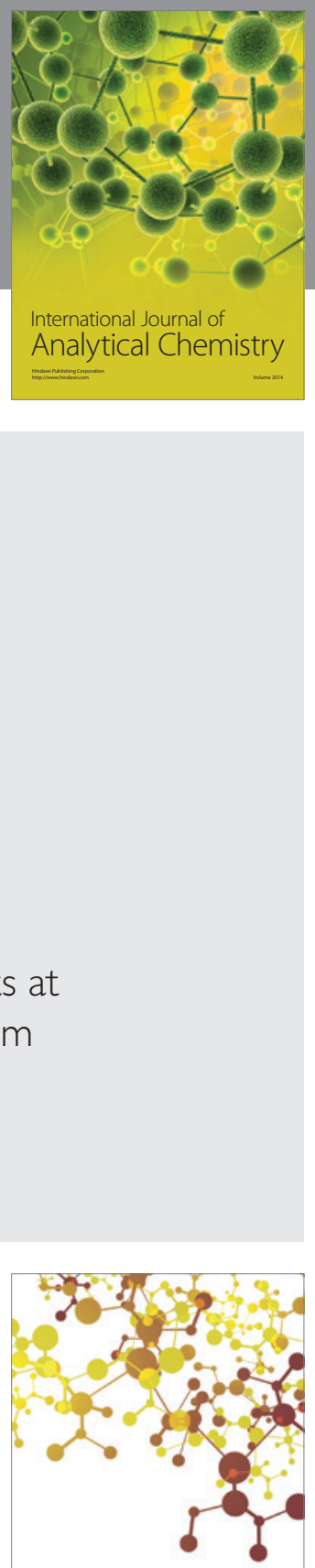

Journal of

Applied Chemistry
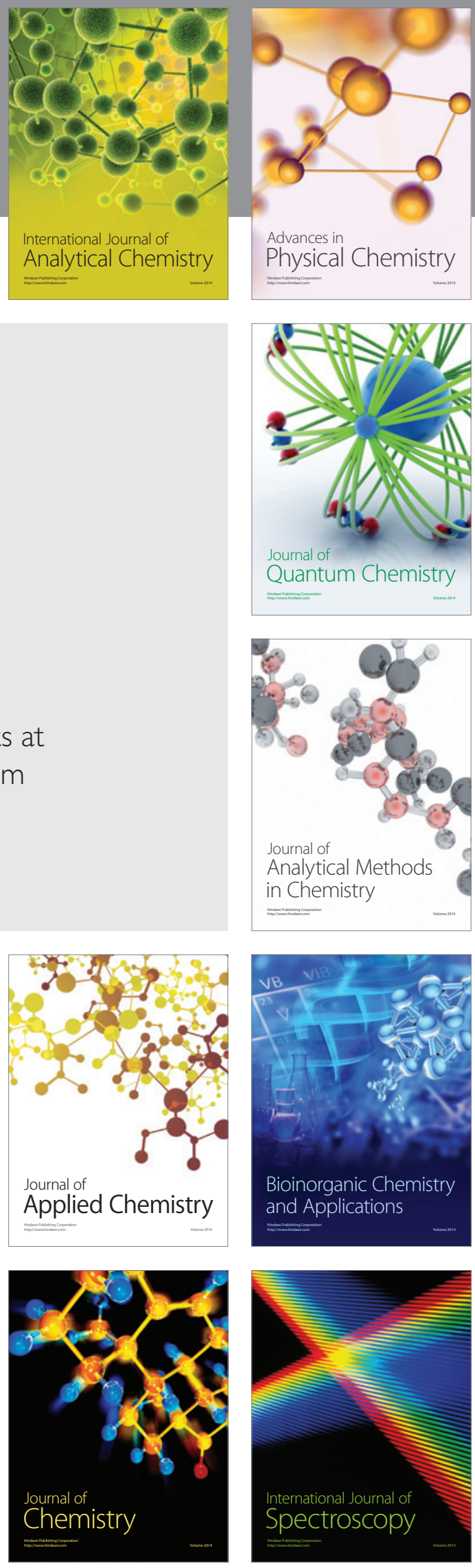